\title{
Factors Affecting the Structural Behavior of FRP Wrapped Concrete Columns and Applications in Design
}

\author{
Shijia Huang ${ }^{1}$ \\ ${ }^{1}$ Civil and Environmental Engineering, Zhejiang University/University of Illinois at Urbana-Champaign Institute, Haining, Zhejiang, \\ 314400, China
}

\begin{abstract}
In this paper, the FRP wrapped concrete column is investigated. . According to the research results of Shan et al. (2020) [2], Li et al. (2006) [3], and Deb et al. (2010) [4], this paper analyzes the variables that need to be controlled in the design of columns from these three perspectives: the shape of the cross-section, fiber orientation and bonding between the concrete column and FRP confinement. Impact tests and compressive tests are performed on different specimen. The setting of different samples follows the principle of controlling variables. The results indicate that FRP-wrapped columns with a circular cross-section are better than that with square or rectangular columns and basalt FRP is the optimal FRP material for strengthening the concrete column under the impact. Fiber orientation and types of bonding layers have a great impact on the mechanical properties of FRP wrapped concrete columns.
\end{abstract}

\section{Introduction}

Fiber Reinforced Polymer (FRP) is composed of a polymer matrix and fibers. This composite material has the characteristics of high strength to weight ratio and high stiffness to weight ratio. Besides, it has a strong resistance to high temperature, corrosion, fatigue and creep. Based on the above characteristics, FRP has been widely used in construction in recent decades. Common FRP includes glass fiber reinforced composites (GFRP), carbon fiber reinforced composites (CFRP), and aramid fiber-reinforced composites (AFRP).

FRP wrapped concrete column, which is composed of three kinds of materials: FRP, concrete, and steel. FRP wrapped concrete column is a structure formed by casting concrete in the tube with a prefabricated FRP barrel as a template. FRP wrapped concrete columns can make full use of the characteristics of each component material and improve the mechanical properties of columns significantly. Compared with the ordinary concrete column, this structure has the following advantages: Firstly, FRP protects the steel and concrete, improve the durability of the structure; secondly, FRP is used as the strengthening material of core concrete in the horizontal direction to improve the bearing capacity of members. Some schematic designs for FRP wrapped concrete columns are shown in Figure 1.

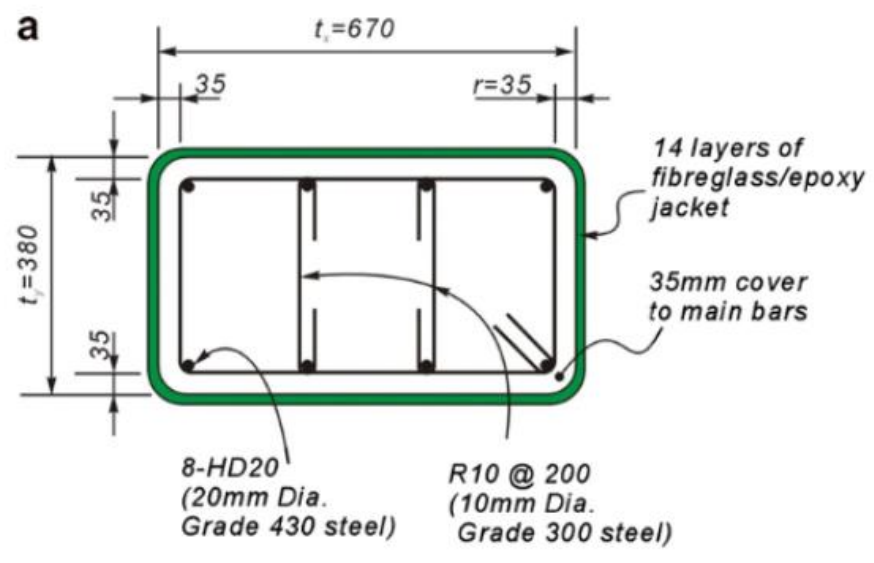

Fig. 1. Schematic Designs for FRP Wrapped Concrete Columns[1]. 
In this paper, based on the results of previous studies on the mechanical properties of FRP wrapped concrete columns, including the study on FRP wrapped concrete columns with different cross-section shapes[2], the study on the effect of fiber orientation on the structural behavior of FRP wrapped concrete cylinders[3], the study on the connection method between FRP and concrete[4], the main factors affecting the mechanical properties of FRP wrapped concrete columns will be analyzed and the corresponding points of the FRP-concrete composite column design will be summarized. Due to the lack of practical experience, a major problem faced by engineers is the lack of standards for FRP composite structure design, so the application of FRP in engineering is still limited. The paper aims to provide some references for the structural design of FRP wrapped concrete columns and promote the use of FRP-concrete columns in construction.

\section{Analysis}

\subsection{Shape of the Cross Section}

Experimental research on FRP-wrapped square or rectangular columns is relatively few compared with those on circular section columns. Moreover, concrete columns often need to resist axial impact force in practical application. For example, concrete columns in subway engineering are often subjected to the impact force of high-speed moving subway. There are few tests on the impact resistance of FRP wrapped concrete columns. Considering the above situation, an experiment was designed and carried out by Shan et al. (2020) [2] to explore the relationship between the axial impact behaviors of FRP-wrapped square columns and the corner radius ratio, which is defined as the ratio of the corner radius and one half of side length. The

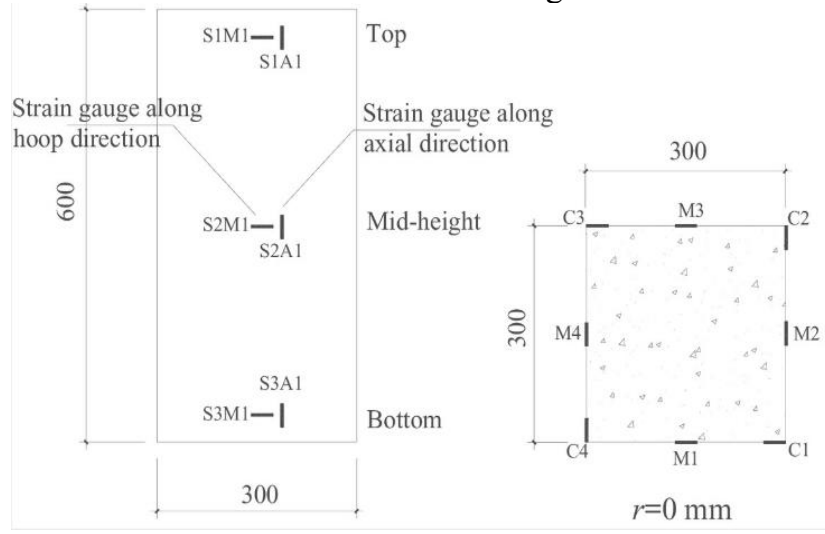

experimental sample settings for a total of 36 columns are presented in Figure 2, Table 1 and Table 2. The testing equipment is shown in Figure 3 and the data collected in the test is shown in Table 3. By analyzing experimental phenomena and drawing images from the experimental data, which can be found in Shan's paper [2], the experimental conclusions are as follows:

Firstly, the corner radius ratio, the number of FRP layers, and the types of FRP have no obvious influence on the failure of FRP wrapped square concrete column under axial impact. The experimental results show that all FRP wrapped square columns have a serious rupture in the chamfered area, which indicates that the failure of FRP wrapped square columns were heavily influenced by the stress concentration at the corner.

Secondly, the axial impact behaviors of FRP wrapped concrete columns were influenced by the corner radius ratio. According to the experimental results, it can be proved that the closer the cross-section shape of the sample is to the circle, the better the strengthening effect of FRP wraps on concrete columns will be. When the corner radius ratio of the specimen increases, both of the impact strength of the specimen and the duration before failure increase. Thus, it proves that larger corner radius ratios can enhance the strengthening effect of FRP wraps on the concrete column.

Thirdly, when other variables that may influence the impact test are limited, the experimental results show that the GFRP wrapped columns and BFRP wrapped columns have a better ability to resist impact and absorb energy compared with CFRP wrapped columns. It shows that deformable FRPs perform better than stiffer FRPs in strengthening the concrete column under the impact. BFRP is the optimal FRP material for strengthening the concrete column under the impact.

Fig. 2. The Experimental Sample for Shan et al. Experiment[2]. 


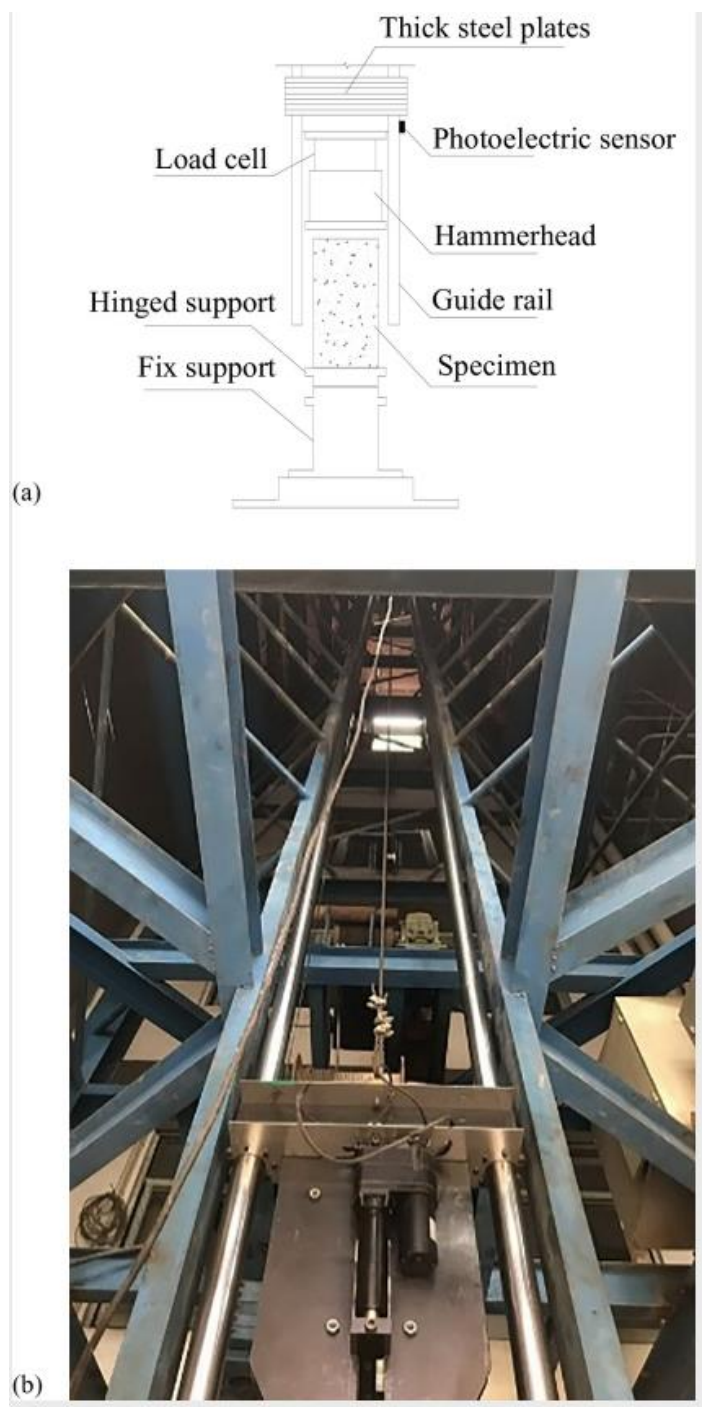

Fig. 3. The Testing Equipment for Shan et al. Experiment[2]. Table 1. Test Matrix for Shan et al. Experiment[2].

\begin{tabular}{lcccccc}
\hline \multirow{2}{*}{$\begin{array}{l}\text { Type of specimen } \\
\text { Unconfined }\end{array}$} & $\begin{array}{c}\text { Specimen (3 } \\
\text { replicates) }\end{array}$ & $\begin{array}{c}\text { Type of } \\
\text { FRP }\end{array}$ & $\begin{array}{c}\text { FRP } \\
\text { layers }\end{array}$ & $\begin{array}{c}\text { Corner radius } \\
(\mathrm{mm})\end{array}$ & $\begin{array}{c}\text { Drop height } \\
(\mathrm{m})\end{array}$ & $\begin{array}{c}\text { Impact energy } \\
(\mathrm{kJ})\end{array}$ \\
corners & UR150 & - & - & 150 & 6 & 53.1 \\
& C3R0 & CFRP & 3 & 0 & 6 & 53.1 \\
& & & & & & \\
& C3R15 & CFRP & 3 & 15 & 6 & 53.1 \\
& C3R30 & CFRP & 3 & 30 & 6 & 53.1 \\
& C3R60 & CFRP & 3 & 60 & 6 & 53.1 \\
C3R90 & CFRP & 3 & 90 & 6 & 53.1 \\
& C3R120 & CFRP & 3 & 120 & 6 & 53.1 \\
& C2R150 & CFRP & 2 & 150 & 6 & 53.1 \\
& C3R150 & CFRP & 3 & 150 & 6 & 53.1 \\
& C4R150 & CFRP & 4 & 150 & 6 & 53.1 \\
& G5R150 & GFRP & 5 & 150 & 7 & 61.9 \\
& B6R150 & BFRP & 6 & 150 & 7 & 61.9 \\
\hline
\end{tabular}

Note: Specimen name designation: type (U, C, G, and B, which denote unconfined, carbon, glass, and basalt, respectively), followed by the number of layers; then, $\mathrm{R}$ followed by the corner radius in $\mathrm{mm}$. For instance, C3R60 means a specimen wrapped by three layers of CFRP with corner radius of $60 \mathrm{~mm}$. Corner radius of $0 \mathrm{~mm}$ denotes a square cross section, while $150 \mathrm{~mm}$ denotes a circular cross section. 
Table 2. Test Matrix for Shan et al. Experiment[2].

\begin{tabular}{lcccc}
\hline Type & $t_{f}(\mathrm{~mm})$ & $f_{f}(\mathrm{MPa})$ & $E_{f}(\mathrm{GPa})$ & $\varepsilon_{f u}(\%)$ \\
CFRP & 0.167 & 3,587 & 236 & 1.52 \\
GFRP & 0.169 & 1,430 & 78 & 1.83 \\
BFRP & 0.107 & 1,933 & 90 & 2.15 \\
\hline
\end{tabular}

Note: $t_{f}=$ nominal thickness; $f_{f}=$ ultimate strength; $E_{f}=$ tensile modulus; and $\varepsilon_{f u}=$ ultimate strain

Table 3. Test Results for Shan et al. Experiment[2].

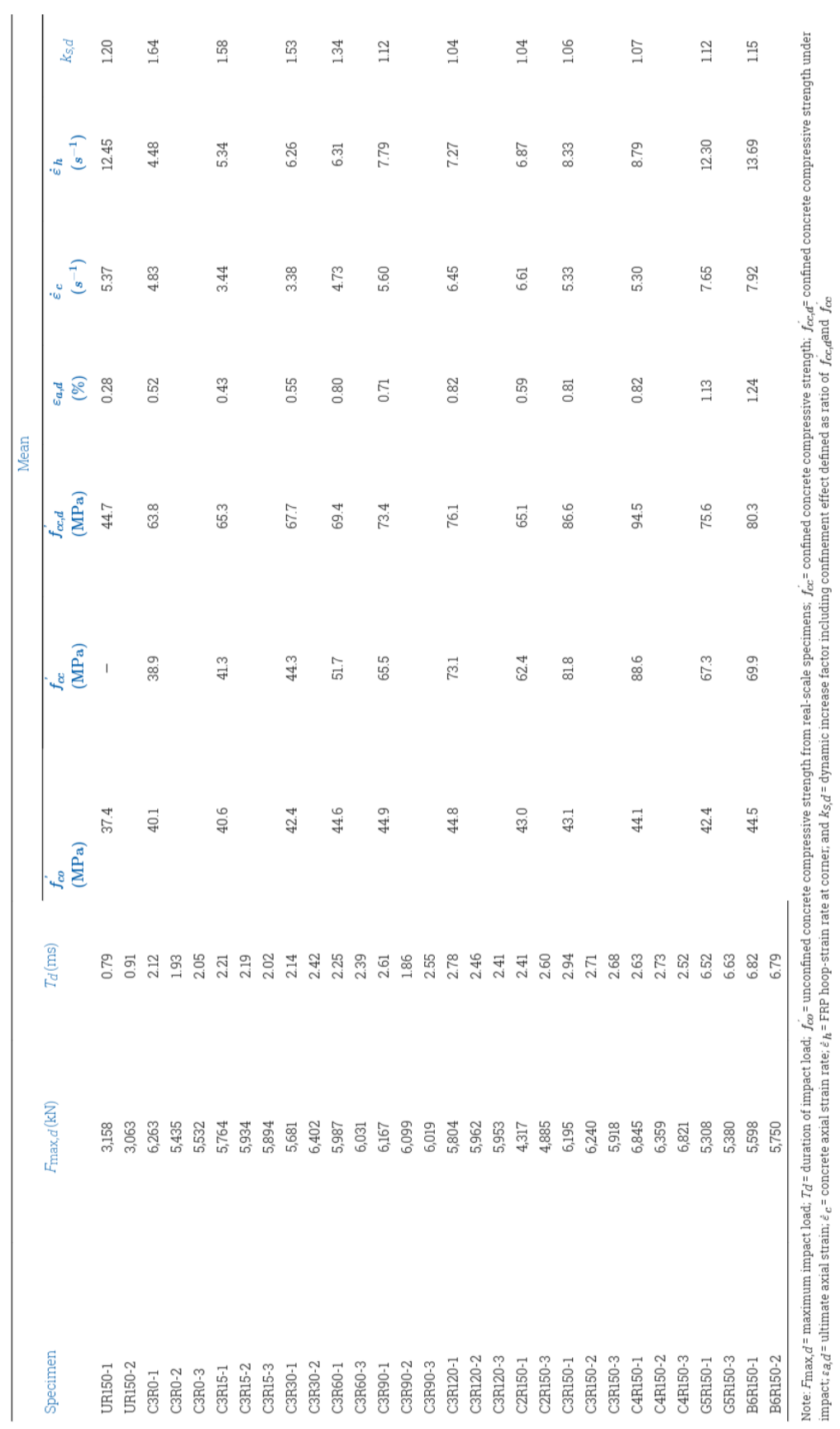

\subsection{Fiber Orientation}

In the structural design of FRP wrapped concrete columns, fiber orientation is very important. Fiber orientation changes cause significant differences in the mechanical properties of the columns. Because almost all the columns are subjected to an eccentric axial load instead of a precise centric axial load, according to theoretical analysis, it is equivalent to a co-axial compressive load and a bending moment. Therefore, in the actual situation, most of the columns should be used as both beams and columns. Fibers are set in hoop 
direction when an only co-axial compressive load is applied. Besides, fibers should be set in the axial direction when a bending moment is applied. When both of the co-axial compressive load and the bending moment are applied, the fiber orientation needs to be designed carefully to maximize the structural capacity of FRP. Considering the above situation, an experiment was designed and carried out by Li et al. (2006) [3] to explore the relationship between the structural behavior of FRP wrapped concrete cylinders and fiber orientation. The experimental specimens contain a total of 27 columns, in which the setting of 24 specimens is presented in Table 4 and the other three specimens were used as control. In the experiment, all test specimens are cylinders with a diameter of $152.4 \mathrm{~mm}$ and a height of $304.8 \mathrm{~mm}$. The testing equipment is shown in Figure 4 and the data collected in the test are shown in Table 5. By analyzing experimental phenomena and drawing images from the experimental data, which can be found in Li's paper [3], the experimental conclusions are as follows:

Firstly, the fiber orientation and FRP wall thickness are important variables in the design of FRP wrapped concrete column. They have a big impact on the stress-strain behavior. Besides, the strength, ductility, and failure mode of wrapped concrete columns are also influenced by them. [3]

Secondly, when fibers form a certain angle between the hoop and axial direction, it will cause the compressive strength and ductility of wrapped concrete columns to decrease. Thus, this situation should be avoided in the future design of FRP wrapped concrete column.

Thirdly, due to the lack of experimental sample data, the current experimental conclusions have limitations. The exploration of fiber orientation should be further developed in the future, for example, similar experiments should be repeated for multiple FRP materials.

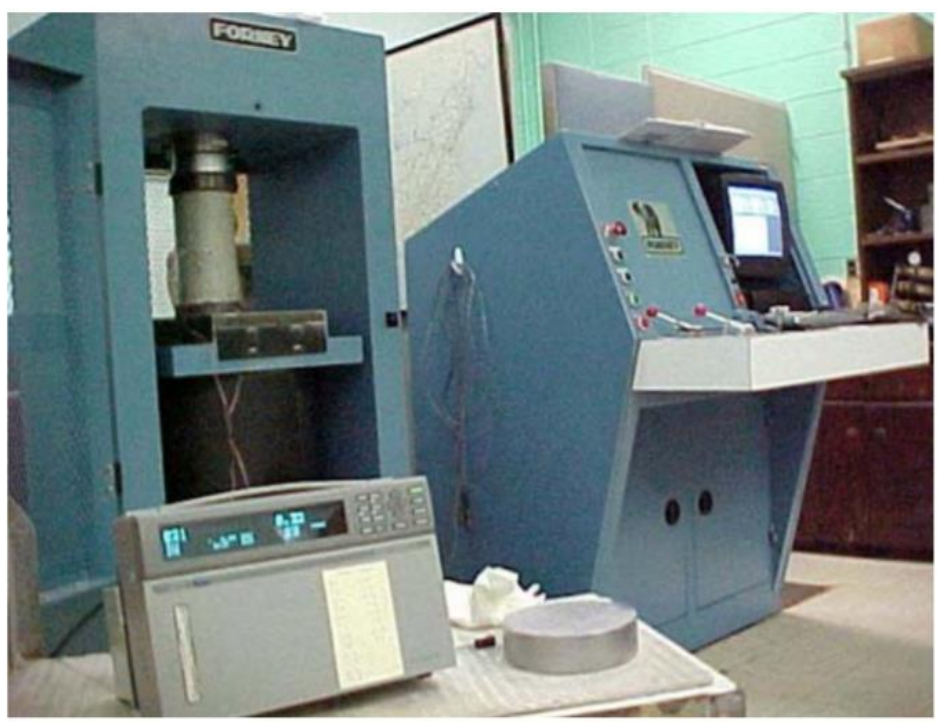

Fig. 4. The Testing Equipment for Li et al. Experiment[3].

Table 4. Test Matrix for Li et al. Experiment[3].

Fiber orientation for each group of concrete columns

\begin{tabular}{|c|c|c|c|c|c|c|c|c|}
\hline Group no. & 1 & 2 & 3 & 4 & 5 & 6 & 7 & 8 \\
\hline Fiber orientation & $0^{\circ} / 0^{\circ}$ & $0^{\circ} / 90^{\circ}$ & $90^{\circ} / 90^{\circ}$ & $60^{\circ} / 30^{\circ}$ & $45^{\circ} / 45^{\circ}$ & $-45^{\circ} / 45^{\circ}$ & $0^{\circ} / 0^{\circ} / 0^{\circ} / 0^{\circ}$ & $90^{\circ} / 90^{\circ} / 90^{\circ} / 90^{\circ}$ \\
\hline
\end{tabular}

Table 5. Test Results for Li et al. Experiment[3]. Summary of test results

\begin{tabular}{ll}
\hline Fiber orientation & Compressive strength $(\mathrm{MPa})$ \\
\hline $0^{\circ} / 0^{\circ}$ & 49.40 \\
$0^{\circ} / 90^{\circ}$ & 48.67 \\
$90^{\circ} / 90^{\circ}$ & 47.61 \\
$60^{\circ} / 30^{\circ}$ & 46.12 \\
$45^{\circ} / 45^{\circ}$ & 46.72 \\
$-45^{\circ} / 45^{\circ}$ & 46.75 \\
$90^{\circ} / 90^{\circ} / 90^{\circ} / 90^{\circ}$ & 48.91 \\
$0^{\circ} / 0^{\circ} / 0^{\circ} / 0^{\circ}$ & 54.62 \\
Control & 45.60 \\
\hline
\end{tabular}

\subsection{Bonding between Concrete Column and FRP Confinement}

The FRP wrapped concrete column is composed of a concrete column, an intermediate epoxy layer, and fiber-reinforced polymer (FRP) confinement. The bonding layer that connects the concrete column and FRP confinement is important and will cause significant differences in the mechanical properties of the columns. A series of numerical experiments have been carried out to investigate the relationship between the type of bond and the mechanical properties of the concrete columns. The investigation performed by Deb et al. (2010) [4] collects the relevant experimental results. The types of interfacial behavior considered in the investigation include three aspects.. First one is the rigidity, which refers to the rigid bond of two layers. The second and the third are the cohesive compliant and unbonded contact, which allow the relative motion between layers. What is 
more, the cohesive bond can not only resist interpenetration between the layers, but also prevent the separation and tangential sliding between the layers. Besides, the unbonded contact can resist the interpenetration between different layers, while it cannot resist the separation and the relative sliding between the layers. And the following conclusions are obtained:

The failure load and ultimate strain of FRP wrapped concrete columns are affected by the types of bond [5]. The largest increase in the failure load is caused by rigid bond and the least increase in the failure load is caused by unbonded contact.

The increase in the failure load caused by cohesive bonds is smaller than the one caused by rigid bonds, but the ultimate strains caused by cohesive bonds are higher than the one caused by rigid bonds. The experimental results show that the bonding between the concrete column and FRP confinement can increase the concrete column strength.

\section{Results and discussion}

The following conclusions provide some suggestions for the design of FRP wrapped concrete columns from three aspects: the shape of the cross-section, fiber orientation, and bonding between the concrete column and FRP confinement.

In the impact test, larger corner radius ratios of the cross section for square column enhance the strengthening effect of FRP wraps on the concrete column. The impact resistance of FRP-wrapped circular columns is better than that of FRP-wrapped square or rectangular columns. Compared with glass FRP (GFRP) and carbon FRP(CFRP), basalt FRP(BFRP) is the optimal FRP material for strengthening the concrete column under the impact.

Besides, proper fiber orientation and sufficient wall thickness effectively strengthen the wrapped concrete columns. When designing fibers orientation, the hoop and axial direction should be avoided to form a certain angle, which might cause the decrease of compressive strength and ductility of wrapped concrete columns. However, the above experimental results are limited to the case where the column is subjected to only axial impact. When the column is subjected to forces in multiple directions, the design for fiber orientation needs to be further studied.

In addition, different types of bond have a great impact on the failure load and ultimate strain of FRP wrapped concrete columns. The bonding between the concrete column and FRP confinement can increase the concrete column strength. Rank the three interfacial behavior from most to least based on how much the failure load of the column is increased: rigid bond, cohesive bond, and unbonded contact. However, the ultimate strains caused by cohesive bonds are higher than those caused by rigid bonds.

\section{Conclusion}

The shape of the cross-section, fiber orientation, and bonding between the concrete column and FRP confinement are important factors affecting the structural behavior of FRP wrapped concrete column. In the design process of FRP wrapped concrete column, the above experimental results can be used to determine the shape of the cross-section, the type of FRP materials, fiber orientation arrangement, and bonding between the concrete column and FRP confinement according to the specific property requirements of the column in different situations.

However, the experimental results of fiber orientation are limited to the case where the column is subjected to only axial impact. In a real situation, such as an earthquake, the force on the column would come from multiple directions. Therefore, under the condition that the column is subjected to forces in multiple directions, the corresponding design scheme for fiber orientation needs to be further tested and studied.

\section{Acknowledgments}

Thanks to my teachers for giving me advice of great value and inspiration of new ideas. Thanks to Jiabin Chen, for providing help in professional knowledge. Thanks to Yvonne Lee, for giving me advice in writing.

\section{References}

1. Y. Wang, K. Hsu. Design of FRP-wrapped reinforced concrete columns for enhancing axial load carrying capacity. Composite Structures. 82(1) (2008) 132-139.

2. B. Shan, Y. Zhang, G. Monti, T. Li and Y. Xiao. Axial Impact Behavior of FRP-Confined Concrete Stub Columns with Square and Circular Cross Section. Journal of Composites for Construction. 24(3) (2020) 04020013.

3. G. Li, D. Maricherla, K. Singh, S. Pang and M. John. Effect of fiber orientation on the structural behavior of FRP wrapped concrete cylinders. Composite Structures. 74(4) (2006) 475-483.

4. A. Deb, S. Bhattacharyya. Investigation into the Effect of Bonding on FRP-Wrapped Cylindrical Concrete Columns. Journal of Composites for Construction. 14(6) (2010) 706-719.

5. L. Yan, A. Duchez, and N. Chouw. Effect of bond on compressive behaviour of flax fibre reinforced polymer tube-confined coir fibre reinforced concrete. Journal of Rnforced Plastics and Composites. 32(4) (2012)273-285. 